\title{
Aspects of Correction of Ametropiya in Children Congenital Cataracts
}

\author{
Narzullayeva Dildora Uktamovna* and Khamraeva Lola Salimovna \\ Tashkent Pediatric Medical Institute Tashkent
}

*Corresponding author: Narzullayeva Dildora Uktamovna, Tashkent Pediatric Medical Institute Tashkent, Republic of Uzbekistan

\section{Introduction}

Congenital cataract (CC)is the most common cause of treatable childhood blindness. It is responsible for $5-20 \%$ of the cases of blindness worldwide. However, the incidence of visual impairment may be higher in developing countries [1]. The prevalence of childhood cataract varies from 1.2 to 6.0 cases per 10,000 infants. Pediatric cataracts are responsible for more than one million cases of childhood blind- ness in Asia. In developing countries, such as India, $7.4-15.3 \%$ of childhood blindness is due to cataracts $[2,3]$. Therefore timely removal of a cataract with the subsequent fast visual rehabilitation has paramount value for children. The Congenital Cataracts take an important place in structure of blindness and low vision and are one of the main reasons for disability on sight since the childhood. Now the cataract of children is one of current problems of children's ophthalmology considering its rather high prevalence and a significant role in structure of blindness and low vision.

As a consequence of lenticular opacity, the development of the visual analyzer is disturbed and amblyopia is formed, the treatment of which requires significant and long-term efforts on the part of ophthalmologists and parents. Among the causes of blindness in children for the share of congenial cataracts falls from 7,5 (in economicallt developed countries) upto $27,4 \%$ (in socially deprived regions). The prevalence of cataracts in developed countries, as well as in Russia makes 1,6-2,4 per 100000 children [4].

Due to the early violation of the correct development of an organ of vision, a delay of normal psychological formation of the personality and high level of an invalidization restoration of sight at children with a cataract is an important problem of ophthalmology. An important point after extraction of CC is the early, full and constant korretion of an afakiya promoting normal maturing of the central mechanisms of the touch analysis on the basis of which process of visual perception is implemented [5]. There are several reasons for which the correction of aphakia differs between children and adults. First, a child's eye is still growing during the first few years of life and during early childhood, the refractive elements of the eye undergo radical changes. Second, the immature visual system in young children puts them at risk of developing amblyopia if visual input is defocused or unequal between the two eyes. Third, the incidence of many complications, in which certain risks are acceptable in adults, is unacceptable in children [6].

Currently, the only type of treatment of a cataract is surgical intervention. Modern tactics of maintaining children with CC is based on early surgical treatment. In surgical treatment of CC for many years technology of the operation was improved [7]. One of the most important is the issue of the timing of surgical measures at CC. At present most of the authors adhere to the opinion, that total, lamellar and cantral cataracts with the area of opacification more than $2.5 \mathrm{~mm}$ should be operated within first three monhts after the birth of a child [8-11], and at the paracentral and central cataracts less than $2.5 \mathrm{~mm}$ in the diameter-perhaps dynamic observation. Such differentiated approach is caused, first of all, by high risk of carrying out surgical intervention, especially at small children and, undoubtedly, complexity of selection of adequate correction of an afakiya that can aggravate already available violations of binocular interaction $[4,12]$.

Currently, the question of expediency of excision of the posterior capsule during extraction of CC remains debatable. According to the data of the number of authors single-step posterior capsulorhexis does not prevent the development of secondary cataracts, which is preconditioned by the high regeneratory ability of the child's eye, that is why it is recommended to to primarily preserve the transparent posterior capsule in order to prevent inflammatory reactions, stabilization of the crystalline humor and intraocular lenses (if it's implanted) and other complications. And in the future, the second stage, if the posterior capsule has gone dull witin the time, to perform YAG-laser (laser on yttrium-aluminium garnet, activated by the neodymium) or surgical posterior capsulotomy. Other authors inform about the primary posterior capsulotomy at planned aphakia or pseudophakia in order to prevent the development of secondary cataracts, as well in small children, who are not capable of dealing with YAG-laser capsulotomy without anesthesia [13]. 
The first implantation of intraocular lenses (IOL) at children in the early fifties carried out E. Epstein and P. Choyce [14]. Also, a controversial issue in surgery of CC is the method of correction of aphakia -there is no any concurrent view yet, assuming a systematic approach to the issue of correction of aphakia. Removal of cataract is necessary to perform simultaneously with full, constant, more physiological correction of aphakia, which ensures ingress of a clearly focused image into the retine, receipt of full-fledged signals in the optic nerve and promoting normal maturation of the central mechanisms of sensory analysis. However, there are two alternative methods of correction of aphakia: using IOL and soft contact lenses (SCL). Each of them has its advantages and shortcomings.

Intraocular correction a more physiological, provides continuous early correction, many studies have shown the effectiveness (reduction of aniseikonia size 2.5 times, high frequency of recovery of binocular vision), good tolerance and safety of IOL. Therefore, most surgeons use use only intraocular correction as a primary optical correction [9].

Multiple studies have shown that it may be technically feasible to implant an IOL shortly after birth, but outcomes have not dramatically improved and the rate of adverse events has increased. Recently, the prospective Infantile Aphakia Treatment Study (IATS) has reported no significant benefit in this approach, with the conclusion by Plager et al. [12] that surgeons should exercise caution when considering IOL implantation in children younger than 7 months.

However, some authors do not implant IOL to children before 18 months of life, and at the age between $18-24$ months under special sircumstances (for example, lack the chance to use SCL) and only at ACC and without comorbidity in the form of microphthalmia [4]. Other authors incline to application of contact correction of an aphakia, including it in the first corrective way which undoubted advantage is the possibility of modeling of refraction effect in the growing eye of the child $[3,15]$. However, apart from the wellknown negative aspects of exposured correction (microtrauma, development of infectious complications, individual intolerance) in children of an early age, there is a problem of compliance with the continuity of correction, the frequency of incidence of which increaes with age, also the replacement of dioptricity at exial eye growth and change of refringance. But the uncorrected aphakia is equal to the non-operated CC [16].

These literatures on postoperative complications at intraocular and contact correction (secondary glaucoma, ocular hypertension, manifest deviation, inflammatory reaction, secondary cataracts, dihescence, pupillary block, IOL dislocation, detached retina, erosion, corneal ulcer, keratopathy) after extraction of CC are various which also change depending on the period of observation [14]. However, there is still no single approach in choosing the method of correction of aphakia [9]. The most optimal correction of aphakia at the present time is the implantation of the posterior chamber intraocular lens (IOL) [10] now. At the same time, despite existence of a set of formulas of calculation of optical power of IOL, refraction mistakes are one of problems of intraocular correction of a congenital cataract in children and make according to various authors from - 10.0 up to $6.5 \mathrm{D}$ [10].

In the development of visual functions after removal of the CC the adequate correction of aphakia plays an important role, which should be constant and complete, providing an hit of a clearly focused image into the retina, the receipt of full signals to the optic nerve, contributing to the normal maturation of the central mechanisms of sensory analysis [5]. Alternative advanced methods of correction of aphakia are intraocular and exposired, each of which has its advantages and disadvantages [10]. Implantation of IOL in children, though not without disputed issues, has obvious positive result [7].

Many questions are raised by discussions to this day. At description of cataract surgery in children, especially junior group, main particularity is that, that the eye is not fully formed and continues to grow. It causes difficulties in calculation of IOL and sometimes in the surgical equipment. There are nomograms for calculation of IOL in children, but, according to a number of authors, they can be used only in some standard cases. In practice it is necessary to consider the age of the child, bilateralism of a cataract, the status of an ambliopiya, possible difficulties connected with glasses wearing or contact lenses, the hereditary anamnesis, the accompanying general and eye diseases, adequacy and the social status of parents. When doubting of correctness of postoperative vision of a child (care and wearing of contact linses, timely replacement and selection of spectacle correction, competent and regular pleopto-orthoptic treatment), at implanting of intraocular lens it is better to focus on emmetropic refraction, as it is better to get myopia in the perspective with corrected visual acuity, than amblyopia $[17,18]$.

In case of unilateral cataract the prognosis is worse, as the visual analyzer on this side does not develop unlike the healty eye. That is why unilateral cataract should be operated as early as possible: according to the data of some authors (Dr. Packer), within the first 3 weeks of life, as soon as the pediatricians say that the baby can tolerate anesthesia $[19,20]$. Other authors give the period of first 10 weeks of life [21]. Patients with ambilateral cataract can wait for longer from 6 months up to one years old, since both eyes do not see and none of them has the opportunity to dominate over the other one. Aphakia is possible in cases of ambilateral cataract with foloowing implanting of intraocular lens to 4-6-years of age [22]. But even with bilateral cataract waiting is not the best way to get perfect postoperation result. Data on functional results regarding the methods of correction of aphakia are also contradictory and ambiguous [18].

So, in some works at the comparison of aphakia correction methods statistical difference on vision acuity is not observed [4]. In the study of children with unilateral pseudophakia and aphakia, also no any difference is shown and the authors recommend to perform intraocular correction only in those cases where the use of SCL would be more onerous and will result in significant periods of correction absence [23]. However, the study of long-term results of visual acuity after extraction of two-sided CC with and without 
IOL implantation showed the best results in intraocular correction (with IOL implantation vision reduction made $29.0 \%$, without IOL implantation-71.0\%) [1]. Questions related to the calculation of the strength of the implantable intraocular lens remains open to date. When choosing intraocular correction of aphakia, the optical power of IOL is calculated individually for each patient according to the formulas SRK-II, SRK/T, Holliday 1, Vinkhorst, Hoffer Q, Haigis, Ivashina -Kolinko and automated techniques. In this case, the key point is the choice of the target refraction [24].

Difficulties of calculation of optical power of IOL and forecasting of desirable refraction effect of operation are connected with the forthcoming growth of the children's eye which is followed by change of a refraction. L. N. Zubareva, A. L. Moskvichev (1992) identified the age groups by the growth of the anterior - posterior axis of the pseudofakic eye: from 5 to 9 years $2 / 3$ of the growth of the anterior-posterior axis of the eye and 1/3-from 9-10 to 14 years. This necessitates the correction of ametropia of the artificial eye in the long term after surgery. Calculation of the optic power of IOL is performed mainly by the formula SRKII and SRKT, considering sagittal size of the eyeball (APA), refracting power of the cornea and individual constants of the chosen model of IOL, also HofferQ and HolladayI, depending on the age of a child. At the calculation of the optical power of the implanted IOL in children of the first year of life, define the quantity of hypocorrection (from +4,0D to +14,0D) of the optical power of IOL, calculated by the formula, taking into account the optical power of the cornea and difference of the origina; APA and forecasted APAafter completion of a physiological growth of an eye [19].

There are different coints of view when choosing the power of implanted intraocular lens in children: implant IOL, calculated per emmetropia at the moment of surgery, with the following replacement, excimer correction or implant IOL less wit the account of hypocorrection, deductible from the calculated lens per emmetropia at the moment of surgery. None of this methods is perfect. Their drawbacks are the risks of development of ametropia of different level, refractive amblyopia, necessity in repeated surgical intervention at an older age [14].

The literature data presented in relation to the approach to the choice of the optical power of the implanted IOL remain poorly reasoned and contradictory (taking into account the age of children at the moment of surgery, only the size of the axial length of the eye at the time of surgery or bi-and unilateral nature of the $\mathrm{CC}$ ).

In the other work at the unilateral CC it is recommended to choose the optic power of IOL to emmetropia, and at the bilateral CC to implant the lens of such optical power, so the necessary correction does not exceed $\pm 3,0$ dptr. N. F. Bobtova, A. K. Djekov at the choice of the optical power of the implanted IOL forcused on the age of children at the moment of surgery, performing the hypocorrection of IOL in the average to $+7,1 \pm 1,2$ dprt during surgery at the age of up to 6 months, $+4,0 \pm 1,3 \mathrm{dptr}$, during surgery at the age of $7-12$ months and $+2,0 \pm 1,3 \mathrm{dptr}$, in children at the age from 1 to 2 years, «gradually» decreasing to years up to $+1,7 \pm 1,5$ dptr [10]. Similar approach to the calculation of IOL, focusing on the age of children at the moment of surgery, described I. S. Zaydullin, R.
A. Aznabayev: hypocorrection $+10,0-(+12,0)$ dptr in $1-2$ months, $+8,0-(+10,0)$ dptr in $3-6$ months, $+7,0-(+8,0)$ dptr in $7-10$ months, $+5,0-(+6,0)$ dptr in 11-12 months [12] .

Foreign authors, relying on age of children at the time of surgery, $4-6$ week age make calculation of IOL for receiving a refraction $8.00 \mathrm{dptr}$ at babies and $6.00 \mathrm{dpr}$ at babies 6 weeks of life are more senior [25]. Other authors when calculating optical power of the implanted IOL suggested to consider initial sizes of eyes. So, at axial legth up to $22.0 \mathrm{~mm}$ to make hypocorrection $6.0 \mathrm{dptr}$ and at the size of axial length of an eye more than $22.0 \mathrm{~mm}-4.0 \mathrm{dptr}$, or to implant an artificial crystalline lens $22.0 \mathrm{dptr}$ with a axial length of $21.0 \mathrm{~mm}, 24.0 \mathrm{dptr}$ at the size of an eye of $20.0 \mathrm{~mm}, 26.0 \mathrm{dptr}$ at 19.0 $\mathrm{mm}, 27.0 \mathrm{dptr}$ at axial length of $18.0 \mathrm{~mm}$ and $28.0 \mathrm{dptr}$ axial length of $17.0 \mathrm{~mm}$ [26-28].

\section{Conclusion}

Finally, surgery represents a step in the management of cataract in children and the cooperation between parents and ophthalmologists is fundamental to achieve optimal visual rehabilitation. Thus, the issues of optimal correction of ametropia in children after cataract removal to date have not been fully disclosed and require further study.

\section{References}

1. Al Shamrani M, Al Turkmani S (2012) Update intraocular lens implantation in children. Saudi J Ophthalmol 26(3): 271-275.

2. Vasavada AR, Vasavada SA, Bobrova N (2011) Outcomes of pediatric cataract surgery in anterior persistent fetal vasculature. J Cataract Refract Surg 38(5): 849-857.

3. Dandona R, Dandona L (2001) Review of findings of the Andhra Pradesh Eye Disease Study: Policy implications for eye-care services. Indian J Ophthalmol 49(4): 215-234.

4. Pershin KB (2007) Interesting phacoemulsification. Moscow, pp. 77-78.

5. Katargina LA (2016) Pediatric ophthalmology federal clinical guidelines, p. 7-8.

6. Baradaran Rafii A, Shirzadeh E, Eslani M, Akbari M (2014) Optical correction of aphakia in children. J Ophthalmic Vis Res 9(1): 71-82.

7. Kruglova TB (2013) Features of the calculation of the optical power of an intraocular lens implanted in children of the first year of life with congenital cataracts. Ophthalmology Bulletin 4: 66-69.

8. Aznabaev MT (1987) New methods and effectiveness of cataract microsurgery in children.

9. Bobrova NF (2012) Classification of congenital cataracts (clinical and surgical). Russian Pediatric Ophthalmology 2: 52-57.

10. Neroev VV, Khvatova AV, Sudovskaya TV (2009) Unilateral congenital cataracts in children (clinical classification, indications for operations, terms of surgical treatment). Russian Pediatric Ophthalmology 1: 8-13.

11. Khvatova A (1982) Century Diseases of the lens of the eye in children. L Medicine 130-145.

12. Zaidullin IS, Aznabayev RA (2010) Changing the parameters of the eye in the long-term follow-up after cataract extraction with IOL implantation in children operated between 1 and 12 months of age. Ophthalmosurgery 6: 26-29.

13. Arestova NN (2009) Results, indications and optimal terms of YAG-laser reconstructive surgery of the anterior eye in children. Ophthalmology Bulletin 3: 38-45. 
14. Wilson ME, Saunders RA, Trivedi RH (2009) Pediatric Ophthalmology: Current thought and a practical guide. Berlin Heidelberg: SpringerVerlag, pp. 375-386.

15. Vasiliev AV (2012) Studying the causes of low vision in children with congenital cataracts and modern rehabilitation opportunities for early surgical treatment of this pathology using lens aspiration with IOL implantation. Practical medicine 4: 13-16.

16. Caceres V (2008) Challenging cataract cases Pediatric surgery at a crossroads. Eye World.

17. Zaidullin IS, Aznabayev RA (2010) Changing the parameters of the eye in the long-term follow-up after cataract extraction with IOL implantation in children operated between 1 and 12 months of age. Ophthalmosurgery 6: 26-29.

18. Zaydullin IS (2012) The system of surgical interventions for lens pathology in complicated cases in children, pp. 275.

19. Lipner M, Eileen E, Birch (2010) Surgical tactics for bilateral congenital cataracts. Eye World.

20. Young MP (2012) Relationship between the timing of cataract surgery and development of nystagmus in patients with bilateral infantile cataracts. J AAPOS 16(6): 554-557.

21. Caceres V (2008) Challenging cataract cases Pediatric surgery at a crossroads. EyeWorld.
22. Khvatova A (1982) Century Diseases of the lens of the eye in children. Medicine, pp. 130-145.

23. Lambert SR (2014) Complications in the first 5 years following cataract surgery in infants with and without intraocular lens implantation in the Infant Aphakia Treatment Study. Am J Ophthalmol 158(5): 892-898.

24. Lambert SR (2014) Comparison of contact lens and intraocular lens correction of monocular aphakia during infancy: A randomized clinical trial of HOTV optotype acuity at age 4.5 years and clinical finding at age 5 years. JAMA Ophthalmol 132(6): 676-682.

25. Tartarella MB (2014) The change in axial length in the pseudophakic eye compared to the unoperated fellow eye in children with bilateral cataracts. J AAPOS 18(2): 173-177.

26. Wilson ME (2011) Secondary in-the-bag intraocular lens implantation in children who have been aphakic since early infancy. J AAPOS 15(2): 162-166.

27. Bikbov MM (2010) Intraocular correction of aphakia in young children with congenital cataracts. OGU Bulletin 12: 35-37.

28. Caceres V (2008) Challenging cataract cases Pediatric surgery at a crossroads. EyeWorld.

\section{(C) This work is licensed under Creative}

To Submit Your Article Click Here: Submit Article

DOI: $10.32474 /$ TOOAJ.2019.02.000134

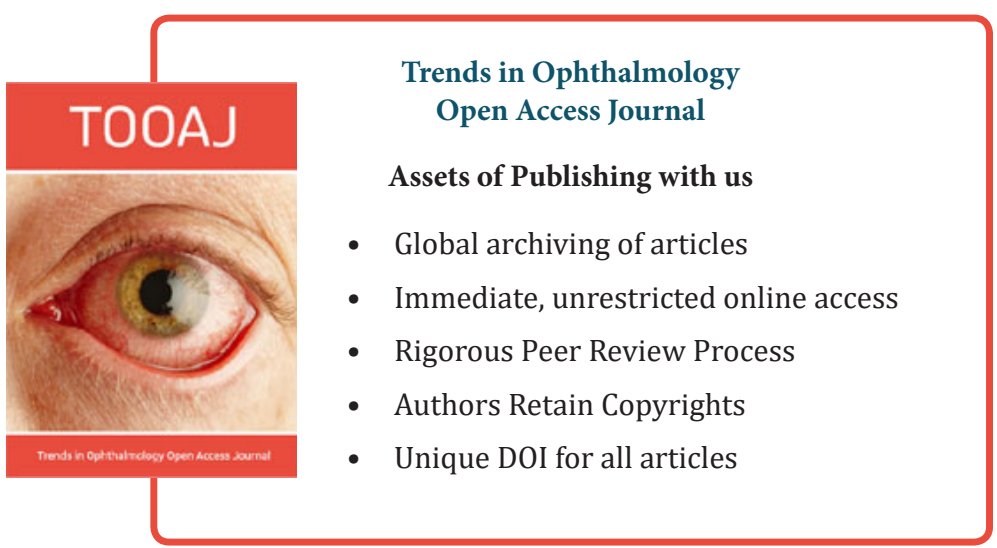

